\section{PC-031 THE TRANSITION FROM THE USE OF BUPIVACAINE TO ROPIVACAINE IN THE DELIVERY ROOM, IN ORDER TO ACHIEVE A BETTER ANALGESIC EFFECT}

${ }^{1} \mathrm{~S}$ Hadad*, ${ }^{2} \mathrm{~A}$ Ataba, ${ }^{3} \mathrm{P}$ Abecassis. ${ }^{1}$ Rambam - Health Care Campus, Pharmaceutical Services - Pharmacy Director, Haifa, Israel; ${ }^{2}$ Rambam Medical Centre, Pharmacy Department, Haifa, Israel; ${ }^{3}$ Rambam Medical Centre, Anaesthesiolgy Department, Haifa, Israel

\subsection{6/ejhpharm-2019-eahpconf.112}

Background Ropivacaine is an amide local anesthestic. It is not a new drug. This drug has the specificity to be less cardiotoxic, with reduced motor blockade, and can be used for regional anaesthesia such as epidural anaesthesia in the delivery room.

In July 2017, it was decided by the pharmaceutical services in Rambam Health Care Campus, together with the anaesthesiologist, to switch to the use of ropivacaine as an alternative to bupivacaine, which had been used for many years in the delivery room.

Purpose The transition from the use of bupivacaine to the use of ropivacaine for the purpose of regional anaesthesia in the delivery room, was carried out in order to achieve a better analgesic effect with minimal motor paralysis compared to bupivacaine.

Material and methods Ropivacaine is commercially available as a solution of $0.2 \%(200 \mathrm{mg} / 100 \mathrm{ml} \mathrm{bag})$. In order to reduce the concentration to $0.1 \%$, the hospital pharmacy added $85 \mathrm{ml}$ of normal saline and $10 \mathrm{ml}(0.5 \mathrm{mg})$ of fentanyl to each ropivacaine bag.

The preparation was done using the aseptic technique, labelled and stored in a refrigerator at $2{ }^{\circ} \mathrm{C}-8^{\circ} \mathrm{C}$, and given a shelf-life of 14 days.

Approximately 300 preparations were prepared each month, and supplied to the delivery room.

Results The administration of low-dose ropivacaine $0.1 \%$ over the same time as an alternative to the administration of bupivacaine at a concentration of $0.125 \%$ gave a very good analgesic effect. In addition, ropivacaine has a reduced motor block in comparison to bupivacaine, which has significant motor block. Conclusion The administration of low-dose ropivacaine $(0.1 \%)$ as a substitute for bupivacaine $(0.125 \%)$ gave a very good analgesic effect. In addition, the anaesthesiologists observed a reduction in motor blockade using ropivacaine in comparison to that of bupivacaine.

\section{REFERENCES AND/OR ACKNOWLEDGEMENTS}

The author thanks the pharmacist team of Rambam Hospital for their assistance in the technical work of sterile preparations.

No conflict of interest.

\section{PC-032 LOW-DOSE MORPHINE SOLUTION FOR SPINAL ANAESTHESIA - READY TO USE TO IMPROVE PATIENT SAFETY IN DRUG THERAPY}

${ }^{1} \mathrm{~K}$ Lämmle*, ${ }^{1} \mathrm{~A}$ Kirchhoff, ${ }^{2} \mathrm{P}$ Hoffmann, 'S Amann. 'München Klinik, Hospital Pharmacy, München, Germany; ${ }^{2}$ München Klinik, Klinik für Anästhesiologie- Operative Intensivmedizin und Schmerztherapie, München, Germany

\subsection{6/ejhpharm-2019-eahpconf.113}

Background Combination with a local anaesthetic agent, such as bupivacaine and a lipophilic opioid such as sufentanil, is frequently used in intrathecal anaesthesia for caesarean section. The combination with low-dose morphine solution 100 to $200 \mu \mathrm{g}$ reduces wound pain after surgery.
No drug with low-dose morphine solution is licensed in Germany. Available products need dilution by factor 100. This two-step diluting procedure involves high risks of contamination and overdosing, the latter resulting in respiratory depression with delayed onset.

Purpose Therefore, anaesthesiologists requested the hospital pharmacy to supply a $100 \mu \mathrm{g} / \mathrm{ml}$ morphine solution for intrathecal administration.

Material and methods Literature research for published formulations, relevant stability criteria and published stability data.

Evaluation of compounding ready-to-administer (RTA) or ready-to-use (RTU) formulations and development of formulation and testing specifications.

Development of a stability indicating RP-HPLC method for determining morphine stability and occurrence of degradation products. Three test batches were examined directly after compounding, after sterilisation, on days 14, 30, 60, 150, 200 and 300 .

Development of a product information and standard operating procedure for clinical use.

Results No published formulations could be found. The $\mathrm{pH}$ and oxygen in sterilised solution could be identified as published criteria limiting stability.

The shelf-life of prefilled syringes for intrathecal administration (RTA) is limited to 24 hour by the risk of microbial contamination and of extraction of syringe material components. Therefore, the decision was in favour of RTU formulation.

A formulation was developed by pharmaceutical principles. Low-dose morphine solution contains morphine hydrochloride trihydrate $100 \mu \mathrm{g} / \mathrm{ml}$ in isotonic sodium chloride solution at $\mathrm{pH}$ 2.8-3.3. After filtration, $2.2 \mathrm{ml}$ of the solution is filled in $5 \mathrm{ml}$ injection vials and autoclaved.

Stability testing proved the stability of the formulation over at least 300 days. No degradation products were detected.

An instruction leaflet, as well as standard operating procedure for safe clinical use of RTU low-dose morphine solution was developed in collaboration with anaesthesiologists and hospital pharmacists

Conclusion Interdisciplinary collaboration of anaesthesiologists and hospital pharmacists enables the development of a simple and stable RTU low-dose morphine formulation for easy application. Patient safety in drug therapy with a high-risk procedure was improved comprehensively.

\section{REFERENCES AND/OR ACKNOWLEDGEMENTS}

McMorrow, et al.

Nguyen-Xuan T, Griffiths W, Kern C, et al.

No conflict of interest.

\section{PC-033 LABELLING WITHOUT STRENGTH FOR A PHARMACEUTICAL PREPARATION USED IN A BLINDED DOSAGE ADJUSTMENT OF CLOZAPINE}

${ }^{1} \mathrm{C}$ Giraudeau*, ${ }^{1} \mathrm{~J}$ Jost, ${ }^{1} \mathrm{M}$ Strumia, ${ }^{1} \mathrm{G}$ Arnaud, ${ }^{2} \mathrm{P}$ Brosset, ${ }^{1} \mathrm{~V}$ Ratsimbazafy. ${ }^{1}$ Dupuytren University Hospital, Pharmacy, 87000 Limoges, France; '²Mother and Child Hospital, Paediatry, 87000 Limoges, France

\subsection{6/ejhpharm-2019-eahpconf.114}

Background Among other items, pharmaceutical preparations labelling must mention the strength of the active ingredient.

However, the clinical state of a 17 -years-old patient on clozapine for schizophrenia required a blinded dosage adjustment to be successful. 